\title{
Non-Economic Events in China and Herding Behavior
}

\author{
Yi-Chang Chen \\ Accounting School, Nanfang College of Sun Yat-sen \\ University, China \\ E-mail: Phdchen7219@gmail.com
}

\author{
Kai-Sheng Chen*, Housen Wang, Chunxiu Qiu, \\ Xinyi Ma \\ *School of Electrical and Computer Engineering, Nanfang \\ College of Sun Yat-sen University, China \\ E-mail: weiweibjqskwx@ hotmail.com \\ *Corresponding author
}

\begin{abstract}
The existence of herding behavior leads to stock price volatility and makes a great influence on the stability of stock market during volatile periods. Many studies have shown that economic events affect herding behavior, while a few studies focus on non-economic events with greater uncertainty especially in China's market. The paper uses cross sectional absolute deviation (CSAD) model to examine whether the non-economic events affect herding behavior. The results show that there are fewer herding phenomena, indicating that non-economic events reduce herding effects in China's market.
\end{abstract}

Keywords-Non-economic Events; CSAD; Herding behavior; Volatility

\section{INTRODUCTION}

Herding is defined as when investors choose to mimic trades they perceive as more informed rather than acting on their own beliefs and personal information (Chang et al., 2000) [2]. This phenomenon is particularly evident among new investors, because new investors are not familiar with the stock market, and they are not confident in their own data, and they are easy to listen to the opinions of most people in decisionmaking, even when they disagree with its predictions (Christie and Huang, 1995) [3].

Previous studies have different test methods for herding. Chang et al., (2000) proposed to use CSAD model to test the herding behavior of different market investors [2]. In addition, Christie and Huang (1995) first proposed CSSD (CrossSectional Standard Deviation) method and found that when there is significant herding behavior, the yield of individual stocks will approach the market yield [3].

For the herding phenomenon, previous studies have taken into account many factors, such as reputation (Holmes et al., 2013; Scharfstein and Stein, 1990) [6] [8], the market fundamentals (Galariotis et al., 2015) [4], and major economic events (Gong and Dai, 2017) [6]. However, major noneconomic events are often affected by other factors and have greater uncertainty. Therefore, whether major non-economic events will affect the behavior of the stock market investors in China, whether it is for stock market investors or market regulators, is of great significance.
The paper transforms the CSAD empirical method proposed by Chang et al. to examine whether the noneconomic events affect herding behavior. For major noneconomic events, this paper selects major political events and major disaster events as representatives for research. Furthermore, five events were selected for research and analysis in these two types of events. The results show that the herding phenomenon is less, indicating that non-economic events reduce herding effects in China's market.

The paper is organized as follows: Section 2 summarizes the results of some researches on the behavior of herdsmen at home and abroad. Section 3 mainly points out the research methods of this paper, the source of research data, and the choice of research objects. Results are presented in Section 4 while Section 5 concludes a discussion of the implications.

\section{LITERATURE REVIEW}

After the 1970s, many domestic and foreign scholars have invested in research on the herding behavior of investors. Christie and Huang (1995) first proposed the CSSD (Cross Sectional Standard Deviation) test method, using the dispersion as an indicator to study the herding behavior of investors [3]. Chang et al., (2000) proposed to use CSAD to test the herding behavior of investors in different markets [2]. In addition, Lakonishok et al., (1992) used LSV (Linear Sweep Voltammetry) method to study 769 stock funds from 1985 to 1989[7]. The results show that not obvious herding behavior was found, except for small stocks.

Holmes et al. (2013) and Scharfstein and Stein (1990) propose that reputation may lead to rational herd behavior [6] [8]. Under other conditions, the herding will be more obvious. For example, Zheng et al., (2017) find that herding is more apparent in both high and low market value industries, in low dividend yield industries and in less concentrated industries [9]. Galariotis et al. (2015) find that investors herd due to both fundamentals and non-fundamentals during different crises [4]. Celiker et al. (2015) find evidence indicating that herding in industries by mutual funds is related to the industry momentum phenomenon [1]. Gong and Dai (2017) found that interest rate increase and Chinese currency $(\mathrm{CNY})$ depreciation will induce herding [5]. 


\section{RESEARCH METHODS}

A. Source and sample processing

This paper will use all stocks of the Shanghai Stock Exchange as research data, and the data used are from the Taiwan Economic Journal.

The event occurrence date $\mathrm{T}$ of the major non-economic events studied in this paper represents the first trading day of the event. If the event is the Chinese stock market trading day and the event occurs before the close, then $\mathrm{T}$ is the day of the event. In addition, $\mathrm{T}$ is the first trading day after the event.

In the information age, investors receive information for a short period of time and respond quickly. Therefore, the research time for investors' herding behavior is the trading day within one week of the event.

\section{B. Selection of major non-economic events}

This paper mainly studies two major non-economic events, major political events and major disaster events. Five events are selected as the research objects for each event. Among them, five major political events, including The 18th CPC Central Committee, The First Plenary Session of the 18th CPC Central Committee, The Second Plenary Session of the 18th Central Committee, The Third Plenary Session of the 18th CPC Central Committee and The Fourth Plenary Session of the 18th CPC Central Committee, were selected as research objects; Five major disaster events, including Wenchuan earthquake in Sichuan, Urumqi smashed and robbed, Yushu earthquake in Qinghai, Ya'an, Sichuan earthquake and Yunnan Ludian earthquake, were selected as research objects.

TABLE I. MAJOR POLITICAL EVENT

\begin{tabular}{|ccc|}
\hline Date & Event & Shanghai index weeks yields \\
\hline November 8-14, 2012 & The 18th CPC Central Committee & $-3.94 \%$ \\
November 15, 2012 & The First Plenary Session of the 18th CPC Central Committee & $-0.74 \%$ \\
February 26-28, 2013 & The Second Plenary Session of the 18th Central Committee & $-1.74 \%$ \\
November 9-12, 2013 & The Third Plenary Session of the 18th CPC Central Committee & $4.47 \%$ \\
October 20-23, 2014 & The Fourth Plenary Session of the 18th CPC Central & $1.15 \%$ \\
& Committee &
\end{tabular}

TABLE II. DISASTER EVENTS

\begin{tabular}{|llc|}
\hline \multicolumn{1}{|c|}{ Date } & Event & Shanghai index weeks yields \\
\hline May 12, 2008 & Wenchuan earthquake in Sichuan & $-2.97 \%$ \\
July 5, 2009 & Urumqi smashed and robbed & $0.73 \%$ \\
April 14, 2010 & Yushu earthquake in Qinghai & $-5.73 \%$ \\
April 20, 2013 & Ya'an, Sichuan earthquake & $-2.62 \%$ \\
August 3, 2014 & Yunnan Ludian earthquake & $0.20 \%$ \\
\hline
\end{tabular}

\section{Herding model}

Currently, the most widely used empirical methods of herding behavior are CSAD (Cross Sectional Absolute Deviation) and CSSD (Cross Sectional Standard Deviation). This paper will use the CSAD method to examine whether major non-economic events affect the herding behavior of Chinese stock market investors.

The specific model expression for CSAD is:

$$
C S A D_{\mathrm{t}}=\frac{1}{N} \sum_{i=1}^{N}\left|R_{i, t}-R_{m, t}\right|
$$

Among them, $R_{\mathrm{i}, t}$ represents the yield of a single stock during the t period, and $R_{m, t}$ represents the average yield of the entire stock market during the t period.

If investors in the stock marke14t tend to imitate the investment behavior of most people and there is a herding behavior, then there is a non-linear relationship between the individual stock returns, CSAD and the market return $\left(R_{m}\right)$.

Therefore, the test method for obtaining herding behavior is:

$$
C S A D_{\mathrm{t}}=\alpha+\beta_{1}\left|R_{m, t}\right|+\beta_{2}\left(R_{m, t}\right)^{2}+\varepsilon_{t}
$$

Examine whether there is a herding behavior in the stock market, as long as it is determined by whether the quadratic coefficient of the regression equation is significantly less than zero. When $\beta_{2}$ is significantly less than zero, there is a significant herding behavior in the market.

Introduce the dummy coefficient D to study whether the occurrence of events affects the herding behavior of investors:

$C S A D_{\mathrm{t}}=\alpha+\beta_{1}\left|R_{m, t}\right|+\beta_{2}\left(R_{m, t}\right)^{2}+\beta_{3} D\left(R_{m, t}\right)^{2}+\varepsilon_{t}$ 
Set $\mathrm{D}$ for the event occurrence date of the study to 1 and set the remaining trading day to 0 .

To examine whether a major non-economic event will affect the herding behavior of stock market investors is only judged by whether $\beta_{3}$ is significantly less than zero. When $\beta_{3}$ is significantly less than zero, it indicates that the significant non-economic event significantly affects the investor's herding behavior.

\section{EMPIRICAL RESULTS AND DATA ANALYSIS}

A. Empirical results

1) Empirical results of major political events

TABLE III. THE 18Th CPC CENTRAL COMMITTEE

\begin{tabular}{|cccccc|}
\hline Time & $\mathrm{a}$ & $\beta_{1}$ & $\beta_{2}$ & $\beta_{3}$ & $\mathrm{R}^{2}$ \\
\hline $\mathrm{T}$ & 0.004 & 6.027 & -86.325 & -116.564 & -0.523 \\
& 0.874 & 0.432 & -0.849 & -82.01 & 0.181 \\
$\mathrm{~T}+1$ & 0.003 & 6.664 & -132.257 & -0.642 & 0.181 \\
& 0.915 & 0.381 & -0.766 & -111.894 & -0.521 \\
$\mathrm{~T}+2$ & 0.003 & 6.744 & -120.675 & -111.522 & -0.522 \\
$\mathrm{~T}+3$ & 0.922 & 0.371 & -0.782 & -116.775 & -0.502 \\
$\mathrm{~T}+4$ & 0.003 & 6.738 & -0.782 & -120.609 & 0.183 \\
\end{tabular}

Note: $\mathrm{T}$ indicates the event occurrence date. *,** and $* * *$ represent statistical significance at the $10 \%, 5 \%$ and $1 \%$ levels, respectively. 2) Empirical results of major disaster events

TABLE IV. WENCHUAN EARTHQUAKE IN SICHUAN

\begin{tabular}{|c|c|c|c|c|c|}
\hline Time & $\mathrm{a}$ & $\beta_{1}$ & $\beta_{2}$ & $\beta_{3}$ & $\mathrm{R}^{2}$ \\
\hline \multirow{2}{*}{$\mathrm{T}$} & 0.005 & 3.559 & -68.328 & 145.482 & 0.246 \\
\hline & 0.732 & 0.053 & -0.087 & 0.943 & \\
\hline \multirow{2}{*}{$\mathrm{T}+1$} & 0.007 & 3.194 & -60.140 & 70.069 & 0.282 \\
\hline & 0.633 & 0.069 & -0.121 & 0.383 & \\
\hline \multirow{2}{*}{$\mathrm{T}+2$} & 0.002 & 4.327 & -83.543 & -49.643 & 0.341 \\
\hline & 0.893 & 0.017 & -0.033 & -0.147 & \\
\hline \multirow{2}{*}{$\mathrm{T}+3$} & 0.002 & 4.303 & -83.152 & -49.196 & 0.340 \\
\hline & 0.877 & 0.017 & -0.034 & -0.151 & \\
\hline \multirow{2}{*}{$\mathrm{T}+4$} & 0.002 & 4.285 & -82.814 & -48.717 & 0.338 \\
\hline & 0.868 & 0.018 & -0.034 & -0.155 & \\
\hline
\end{tabular}

\section{B. Data analysis}

Through the results of the above two sets of data, we can know that major political events and major disasters did not occur in the week of the incident.

In the data set on major political events, we selected five important political events in China, including the 18th National Congress, the first Plenary session of the 18th CPC Central Committee, the second Plenary session of the 18th CPC Central Committee, the third Plenary session of the 18th CPC Central Committee, and the fourth Plenary session of the 18th
CPC Central Committee. Through the empirical research by using CSAD within five trading days, the result shows that the five major political events have no impact on investors' conformity behavior.

In the second group of data which is major catastrophic events, we selected five major domestic disasters, including the Wenchuan earthquake in Sichuan, the Urumqi smashed and robbed, the Yushu earthquake in Qinghai, the Ya'an earthquake in Sichuan, and the Ludian earthquake in Yunnan. For each incident, within a week, that is, within five trading days, CSAD was used for empirical research. The results showed that the 
above five major disaster events did not affect the investor's herding behavior within one week of the incident.

\section{CONCLUSION AND RECOMMENDATIONS}

\section{A. Conclusion}

This paper uses the CSAD empirical research method to empirically study whether the major non-economic events affect the herding behavior of Chinese stock market investors. The CSAD empirical research method was proposed by Chang et al. (2000) ${ }^{[2]}$ and is currently used by most scholars to study herding behavior. However, in the study of the impact of events on the stock market, most scholars use the event research method. In this paper, the CSAD empirical research method proposed by Chang et al. is transformed to study the impact of events on the herding behavior of stock market investors.

For major non-economic events, this paper selects major political events and major disaster events as representatives for research. Furthermore, five events were selected for research and analysis in these two types of events.

It can be seen from the empirical research data that major political events and major disaster events did not appear in the week of the incident.

Therefore, we believe that major non-economic events do not affect the herding behavior of Chinese stock market investors.

\section{B. Recommendations}

Based on the empirical findings of this paper, we propose the following suggestions for follow-up research:

First, this paper takes the occurrence of major noneconomic events within one week as the research object. The follow-up research can be expanded in time to study the impact of the events on the behavior of investors in one month, one quarter, one year and so on.

Second, the major non-economic events studied in this paper are all major events in China. The follow-up study can further study the impact of major international non-economic events on the behavior of investors. Third, the research method adopted in this paper is based on the CSAD, and subsequent research can also be studied by other empirical research methods.

\section{REFERENCES}

[1] Celiker, U., Chowdhury, J., \& Sonaer, G. (2015). Do mutual funds herd in industries? Journal of Banking \& Finance, 52, 1-16.

[2] Chang, E.C., Cheng, J.W., \& Khorana, A. (2000). An examination of herd behavior in equity markets: An international perspective. Journal of Banking \& Finance, 24(10), 1651-1679.

[3] Christie, W.G., \& Huang, R.D. (1995). Following the pied piper: Do individual returns herd around the market? Financial Analysts Journal, 51(4), 31-37.

[4] Galariotis, E.C., Rong, W., \& Spyrou, S.I. (2015). Herding on fundamentalinformation: A comparative study. Journal of Banking \& Finance, 50, 589-598.

[5] Gong, P., \& Dai, J. (2017). Monetary policy, exchange rate fluctuation, and herding behavior in the stock market. Journal of Business Research, 76, 34-43.

[6] Holmes, P., Kallinterakis, V., \& Ferreira, M. L. (2013). Herding in a concentrated market: a question of intent. European Financial Management, 19(3), 497-520.

[7] Lakonishok, J., Shleifer, A., \& Vishny, R.W. (1992). The impact of institutional trading on stock prices. Journal of financial economics, 32(1), 23-43.

[8] Scharfstein, D. S., \& Stein, J. C. (1990). Herd behavior and investment. The American Economic Review, 465-479.

[9] Zheng, D., Li, H., \& Chiang, T.C. (2017). Herding within industries: Evidence from Asian stock markets. International Review of Economics \& Finance, 51, 487-509. 